\title{
Definition of Treatment Targets in Rheumatoid Arthritis: Is It Time for Reappraisal?
}
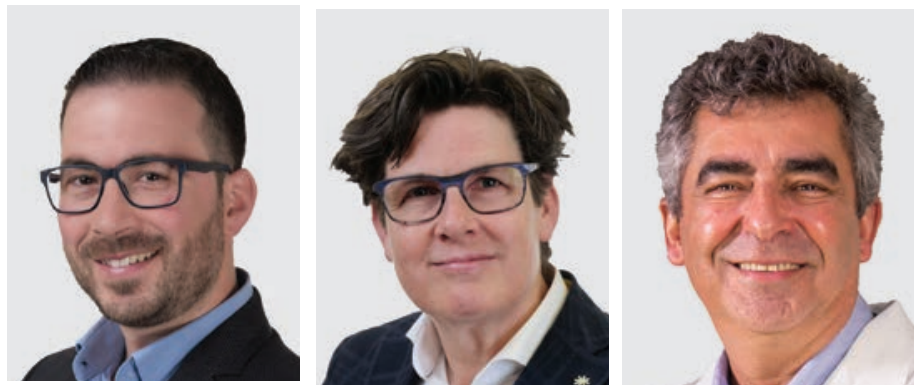

\author{
Ricardo J.O. Ferreira ${ }^{1}$ (D), Robert B.M. Landewé2 (iD), and José A.P. da Silva ${ }^{3}$ (iD)
}

In the current issue of The Journal of Rheumatology, Kremer and colleagues ${ }^{1}$ compare the Clinical Disease Activity Index (CDAI) with a slightly modified Corrona Routine Assessment of Patient Index Data 3 (cRAPID3) in terms of correlation and disease activity categorization, using 2 large US registries of patients with rheumatoid arthritis (RA). Overall, a low concordance between these 2 composite indices $(\kappa=0.29)$ was found in terms of disease activity categories, despite a moderate correlation between their numerical global scores $\left(r_{s}=0.58\right.$ and 0.72 , for the BRASS and CORRONA registries, respectively). The authors provided a correlation matrix of the individual components of these indices, confirming an overall low $\left(r_{s} \leq 0.50\right)$ agreement between physician- and patient-derived domains. The agreement in the classification of patients according to disease activity categories was poor: $34 \%$ of all patients in remission or low disease activity (LDA) according to CDAI $(n=28,991)$ in the CORRONA registry were classified as moderate or high disease

${ }^{I}$ R.J. Ferreira, RN, PhD, Nursing Specialist in Chronic Diseases, Invited Professor, Rheumatology Department, Centro Hospitalar e Universitário de Coimbra, and Health Sciences Research Unit: Nursing (UICiSA:E), Nursing School of Coimbra (ESEnfC), Coimbra, Portugal; ${ }^{2}$ R.B. Landewé, MD, PhD, Rheumatologist, Full Professor of Rheumatology, Rheumatology, Zuyderland Medical Center, Heerlen, and Amsterdam Rheumatology Center, AMC, Amsterdam, the Netherlands; ${ }^{3} J$.A. da Silva, MD, PhD, Rheumatologist, Full Professor of Rheumatology, Head of Department, Rheumatology Department, Centro Hospitalar e Universitário de Coimbra, and Coimbra Institute for Clinical and Biomedical Research (iCBR), Faculty of Medicine, University of Coimbra, Portugal.

The authors have no conflicts of interest.

Photo for RJF courtesy of the European Alliance of Associations for Rheumatology (EULAR).

Address correspondence to Dr. R.J. Ferreira, Serviço de Reumatologia, Consulta Externa, Piso 7, Centro Hospitalar e Universitário de Coimbra, EPE. Avenida Dr. Bissaya Barreto, 3000-075 Coimbra. Portugal.

Email:rferreira@reumahuc.org. activity by cRAPID3. Conversely, among all patients in a "satisfactory" state according to cRAPID3 ( $\mathrm{n}=22,201), 14 \%$ did not reach the target of remission or LDA by the CDAI. The authors concluded that "RAPID3 should not be used as an exclusive measure to evaluate clinical status and inform treatment decisions as the individual components of this metric are highly associated with noninflammatory conditions...and are discordant with CDAI evaluations."

These results are striking in a treat-to-target (T2T) era and justify the authors' conclusion. Treating to target has become a predominant paradigm in the management of RA, supported by statistical evidence of superior efficacy and better long-term outcomes. ${ }^{2,3}$ The provisional definitions of remission, the primary target, endorsed by the American College of Rheumatology and the European Alliance of Associations for Rheumatology (ACR/ EULAR) ${ }^{4}$ in 2011 (Figure 1), were primarily designed for use in clinical trials. However, their application in clinical practice was already predicted in the pivotal paper ${ }^{4}$ and actually became widespread, especially in Europe. This makes the definition of "target" a crucial issue.

The concept of clinical remission is meant to represent a status in which "functional and structural outcomes are maximized," this being most guaranteed in "the absence of signs and symptoms of significant inflammatory disease activity." The ideal definition of target would be stringent enough to entice clinicians to seek the best possible control of inflammation but should also avoid excessive rigor, given the risk of unjustified overtreatment.

All the definitions of remission endorsed by ACR/EULAR include the patient global assessment of disease activity (PtGA). This variable, measured on a visual analog scale of $0-10 \mathrm{~cm}$, has the same weight as the tender and swollen 28-joint counts (TJC28, SJC28), and C-reactive protein (mg/dL). A PtGA of 2 excludes remission in the Boolean definition and a score of 3

\section{See RA, CDAI, and RAPID3, page $x x x$}




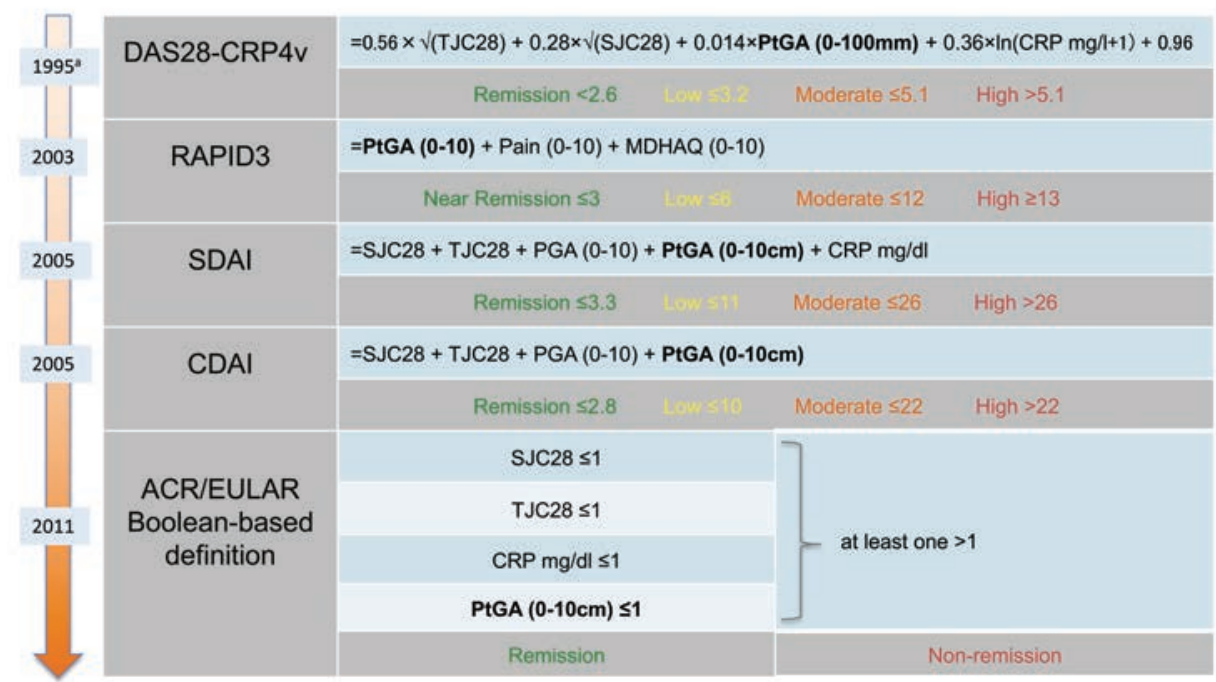

Figure 1. Disease activity measures used in RA. This shows the components and scoring algorithms of 4 disease activity tools currently in use in clinical practice and in clinical trials in RA. They are presented in chronologic order of development. ${ }^{a}$ Although the DAS with 28-joint counts was developed in 1995, its original form with 68/66-joint counts was developed in early 80s. ACR: American College of Rheumatology; CDAI: Clinical Disease Activity Index; CRP: C-reactive protein; DAS28-CRP4v: Disease Activity Score in 28 joints using CRP and 4 variables; In: natural logarithm; EULAR: European League Against Rheumatism; MDHAQ: multidimensional Health Assessment Questionnaire; PtGA: patient global assessment; PGA: physician global assessment; RA: rheumatoid arthritis; RAPID3: Routine Assessment of Patient Index Data 3; SDAI: Simplified Disease Activity Index; SJC28: swollen 28-joint count; TJC28: tender 28-joint count.

makes it virtually impossible in all 3 endorsed definitions and in RAPID3. This relative weight is significantly higher than attributed in the original Disease Activity Score in 28 joints (DAS28). Compelling evidence, supported by systematic literature reviews, confirms that PtGA is the most important factor impeding patients from reaching the Boolean definition of remission. This condition, named PtGA-near-remission, affects around $20 \%$ of all patients with RA and $45-60 \%$ of all those who are otherwise in remission, both in clinical practice ${ }^{6}$ $(\mathrm{n}=23,297)$ and in $\operatorname{trials}^{7}(\mathrm{n}=5792)$.

Does PtGA reflect disease activity closely enough to justify this effect in the current definition of target and ensue management decisions? The ACR/EULAR Committee justified the inclusion of PtGA in the definitions because it separates active treatment from placebo in clinical trials. ${ }^{4}$ In fact, several studies have demonstrated that PtGA has a statistically significant positive correlation with more objective measures of disease activity, ${ }^{8,910,11}$ an observation replicated by Kremer, et al. ${ }^{1}$ However, this correlation is simply absent in the low levels of disease activity, ${ }^{8,9}$ where the categorical definitions leading T2T decisions become critical. At this level, PtGA is not related to disease activity but rather to fatigue, pain, function, and psychological well-being. ${ }^{8,9,11}$ Curtis, et al, ${ }^{12}$ also using data from the CORRONA registry, revealed that despite the achievement of a meaningful clinical response (decrease $\geq 10$ in CDAI) with a biological agent, many patients failed to exceed the minimum clinically important difference in PtGA, pain, function, and fatigue. Boone, et al clearly depicted, through a 3-year prospective cohort study ( $\mathrm{n}=330$, established RA), that despite a statis- tically significant decrease in DAS28 over time, the RAPID3 remained stable. ${ }^{13}$ These authors also observed that RAPID3 is poorly associated with DAS28 based on erythrocyte sedimentation rate (ESR) in daily practice, mainly due to the weak associations between RAPID3 and the objective components of DAS28 (SJC28 and ESR) ${ }^{14}$; these results are confirmed in the current work by Kremer, et al. ${ }^{1}$

A recent study from our group (Brites, et al, unpublished data) formally demonstrates that PtGA scores $>1$ in patients otherwise in remission $(\mathrm{n}=40)$ are not associated with subclinical inflammation as assessed by extensive ultrasound examination ( 44 joints, 36 tendons, and 4 bursas). Other investigators have reported essentially the same regarding pain and function, also included in RAPID3. ${ }^{15}$ We have also demonstrated that excluding PtGA from the Boolean-based definition of remission does not reduce its ability to predict good structural outcome, a core objective of the concept of remission. ${ }^{7.16}$ In fact, $3 \mathrm{~V}$-remission (i.e., Boolean remission excluding PtGA) showed slightly better predictive accuracy of radiographic progression than "full" 4V-remission, although both definitions were poor predictors of structural damage.

Patients in PtGA-near-remission cannot be expected to further improve by the additional immunosuppressive therapy they would receive if current treatment recommendations are followed strictly. Actually, they would face an unjustifiable risk of overtreatment. Additionally, these patients continue to be deprived of the adjuvant interventions they need to mitigate the persisting effect of disease.

Taken together, the evidence reviewed above makes a 
compelling argument against the concept that a useful and valid definition of remission can be based solely on patient-reported outcome measures (PROMs), as conveyed by RAPID3. They actually question whether any of these PROMs, with emphasis on PtGA, should be part of a definition used to guide and target immunosuppressive therapy.

Of course, it would be totally inappropriate to exclude the patient's perspective from the guidance of therapy, which must remain core to the objectives of medical care. However, we must keep in mind that the current target is blurred by PtGA, exposing patients to the risk of overtreatment, and also that controlling the disease process does not guarantee remission of the effect of disease. This indicates that the patient's perspective is better served by a separate target, guiding remission of effect/ symptoms, once disease remission has been achieved.

This is the foundation for our dual target proposal, ${ }^{8,17}$ with one target focusing on the control of the inflammatory process and the other on the optimization of the patient's condition. Michaud, et al ${ }^{18}$ recently concluded that "the use of patient-reported outcomes in addition to a treat-to-target approach may provide information that will inform a management decision necessary to address residual symptoms." Based on data from the "Care in Early RA" (CareRA) trial, Pazmino, et al suggest that PtGA, pain, function, and fatigue "represent a separate aspect of the disease burden of patients with early RA, which could be further explored as a target for care apart from disease activity." ${ }^{19}$ Selecting the best tools to represent each target seems to be a timely task for the rheumatology community. RAPID3 deserves to be a candidate for the definition of the patient's target, in parallel with other instruments, such as the Patient Experienced Symptom State $(\mathrm{PESS})^{20}$ or the RA Impact of Disease (RAID), ${ }^{21}$ but certainly not for the target guiding immunosuppressive therapy. This debate should distinguish clearly the application of these definitions in clinical trials and in clinical practice and be informed by the limitations of multidimensional composite indices in the care of individual patients. ${ }^{22}$

In conclusion, the evidence seems mature enough to advise a revision of the definition of treatment target(s) in RA. PtGA (as other PROMs) can be either a "friend," if clearly understood by patients and physicians and used according to their intrinsic meaning and psychometric properties, or a "foe" if these conditions are not met, as in composite measures used to guide immunosuppressive therapy. We believe that the consideration of a separate, symptom-based target, would sharpen the definition of remission and foster improved person-centered outcomes beyond disease control.

\section{REFERENCES}

1. Kremer JM, Pappas DA, Kane K, Greenberg J, Harrold L, Feathers VL, et al. The Clinical Disease Activity Index (CDAI) and the Routine Assessment of Patient Index Data3 (RAPID3) for achievement of treatment strategies. J Rheumatol 2021; xxxxxx.

2. Stoffer MA, Schoels MM, Smolen JS, Aletaha D, Breedveld FC, Burmester G, et al. Evidence for treating rheumatoid arthritis to target: results of a systematic literature search update. Ann Rheum Dis $2016 ; 75: 16-22$.
3. Wailoo A, Hock ES, Stevenson M, Martyn-St James M, Rawdin A, Simpson E, et al. The clinical effectiveness and cost-effectiveness of treat-to-target strategies in rheumatoid arthritis: a systematic review and cost-effectiveness analysis. Health Technol Assess 2017; 21:1-258.

4. Felson DT, Smolen JS, Wells G, Zhang B, van Tuyl LH, Funovits J, et al. American College of Rheumatology/European League Against Rheumatism provisional definition of remission in rheumatoid arthritis for clinical trials. Ann Rheum Dis 2011;70:404-13.

5. Smolen JS, Breedveld FC, Burmester GR, Bykerk V, Dougados M, Emery P, et al. Treating rheumatoid arthritis to target: 2014 update of the recommendations of an international task force. Ann Rheum Dis 2015;75:3-15.

6. Ferreira RJ, Santos E, Gossec L, da Silva JA. The patient global assessment in RA precludes the majority of patients otherwise in remission to reach this status in clinical practice. Should we continue to ignore this? Semin Arthritis Rheum 2020;50:583-5.

7. Ferreira RJ, Welsing PM, Jacobs JW, Gossec L, Ndosi M, Machado PM, et al. Revisiting the use of remission criteria for rheumatoid arthritis by excluding patient global assessment: an individual meta-analysis of 5792 patients. Ann Rheum Dis 2020 Oct 6 (E-pub ahead of print).

8. Ferreira RJ, Duarte C, Ndosi M, de Wit M, Gossec L, da Silva JA. Suppressing inflammation in rheumatoid arthritis: does patient global assessment blur the target? A practice-based call for a paradigm change. Arthritis Care Res 2018;70:369-78.

9. Ferreira RJ, Carvalho PD, Ndosi M, Duarte C, Chopra A, Murphy $\mathrm{E}$, et al. Impact of patient's global assessment on achieving remission in patients with rheumatoid arthritis: a multinational study using the METEOR database. Arthritis Care Res 2019;71:1317-25.

10. Ward MM, Guthrie LC, Dasgupta A. Direct and indirect determinants of the patient global assessment in rheumatoid arthritis: differences by level of disease activity. Arthritis Care Res 2017;69:323-9.

11. Radner H, Yoshida K, Tedeschi S, Studenic P, Frits M, Iannaccone C, et al. Different rating of global rheumatoid arthritis disease activity in rheumatoid arthritis patients with multiple morbidities. Arthritis Rheumatol 2017;69:720-7.

12. Curtis JR, Shan Y, Harrold L, Zhang J, Greenberg JD, Reed GW. Patient perspectives on achieving treat-to-target goals: a critical examination of patient-reported outcomes. Arthritis Care Res 2013;65:1707-12.

13. Boone NW, Sepriano A, van der Kuy PH, Janknegt R, Peeters $\mathrm{R}$, Landewé RB. Cotreatment with methotrexate in routine care patients with rheumatoid arthritis receiving biological treatment yields better outcomes over time. RMD Open 2019;5:e000836.

14. Boone NW, Sepriano A, van der Kuy PH, Janknegt R, Peeters $\mathrm{R}$, Landewé RB. Routine Assessment of Patient Index Data 3 (RAPID3) alone is insufficient to monitor disease activity in rheumatoid arthritis in clinical practice. RMD Open 2019;5:e001050.

15. van der Ven M, Kuijper TM, Gerards AH, Tchetverikov I, Weel AE, van Zeben J, et al. No clear association between ultrasound remission and health status in rheumatoid arthritis patients in clinical remission. Rheumatology 2017;56:1276-81.

16. Ferreira RJ, Fautrel B, Saraux A, Gaujoux-Viala C, Rat AC, Guillemin F, et al. Patient global assessment and radiographic progression in early arthritis: 3-year results from the ESPOIR cohort. Arthritis Care Res 2020 Apr 27 (E-pub ahead of print).

17. Ferreira RJ, Ndosi M, de Wit M, Santos EJ, Duarte C, Jacobs JW, et al. Dual target strategy: a proposal to mitigate the risk of overtreatment and enhance patient satisfaction in rheumatoid arthritis. Ann Rheum Dis 2019;78:e109.

18. Michaud K, Pope J, van de Laar M, Curtis JR, Kannowski C, Mitchell S, et al. A systematic literature review of residual symptoms 
and unmet need in patients with rheumatoid arthritis. Arthritis Care Res 2020 Jul 3 (E-pub ahead of print).

19. Pazmino S, Lovik A, Boonen A, De Cock D, Stouten V, Joly J, et al. Does including pain, fatigue, and physical function when assessing patients with early rheumatoid arthritis provide a comprehensive picture of disease burden? J Rheumatol 2021;48:174-8.

20. Duarte C, Santos E, da Silva JA, Kristianslund EK, Kvien TK, Dougados M, et al. The Patient Experienced Symptom State (PESS): a patient-reported global outcome measure that may better reflect disease remission status. Rheumatology 2020;59:3458-67.
21. Gossec L, Paternotte S, Aanerud GJ, Balanescu A, Boumpas DT, Carmona L, et al. Finalisation and validation of the rheumatoid arthritis impact of disease score, a patient-derived composite measure of impact of rheumatoid arthritis: a EULAR initiative. Ann Rheum Dis 2011;70:935-42.

22. Landewé RB, van der Heijde D. Use of multidimensional composite scores in rheumatology: parsimony versus subtlety. Ann Rheum Dis 2020 Nov 3 (E-pub ahead of print). 